\title{
Cognitive Ergonomics of Formgiving as Unstructured Approaches in Furniture Design Practice
}

\author{
Mohd Hasni Chumiran, Shahriman Zainal Abidin, Wan Nuraini Rahim, Verly Veto Vermol \\ Formgiving Design Research Group, Faculty of Art \& Design, \\ Universiti Teknologi MARA, 40450 Shah Alam, Malaysia
}

hasni.chumiran@limkokwing.edu.my, shahriman.z.a@uitm.edu.my, wannuraini@gmail.com, verly@uitm.edu.my Tel of 1st Author: 0193512965

\begin{abstract}
This paper discusses how designers formulate ideas through unstructured approaches in furniture design. The problem arose from a logical analysis of the strategies, methods, and hermeneutics in designing within the state-of-the-art interpretation principle. The goal is to understand how designers interpret the visual concept of subjectivity. In the designers' cognitive ergonomics, verbal protocol analysis approaches methodologically analyzed. The 15-minute memorizing-based videotapes observe the designer reflection using several form properties, namely a characteristic of the uncertain objects has practiced. The findings showed the embodiment of metaphorical forms for designers to visualize unstructured visual forms as significant tangible forms.
\end{abstract}

Keywords: Cognitive ergonomics; formgiving; furniture design; visual protocol

eISSN: 2398-4287@ 2021. The Authors. Published for AMER ABRA cE-Bs by e-International Publishing House, Ltd., UK. This is an open access article under the CC BYNC-ND license (http://creativecommons.org/licenses/by-nc-nd/4.0/). Peer-review under responsibility of AMER (Association of Malaysian Environment-Behaviour Researchers), ABRA (Association of Behavioural Researchers on Asians/Africans/Arabians) and cE-Bs (Centre for Environment-Behaviour Studies), Faculty of Architecture, Planning \& Surveying, Universiti Teknologi MARA, Malaysia.

DOI: https://doi.org/10.21834/ebpj.v6iSl5.2927

\subsection{Introduction}

There are two types of research on ergonomics in the existing current literature. The first type of research focuses on physical ergonomics, and the second on cognitive ergonomics (International Ergonomics Association, 2019). Physical ergonomics is concerned with human anatomical, anthropometric, physiological and biomechanical characteristics as they relate to physical movement. Significant points include working postures, handling of materials, repetitive movements, work-related musculoskeletal disorders, workplace layout, safety and health. Meanwhile, cognitive ergonomics is concerned with mental processes such as perception, memory, reasoning, and motor response as they affect interactions among humans and other elements of a system. Pertinent themes incorporate mental workload, decision-making, skilled performance, human-computer interaction, human reliability, work stress and training as these may relate to human-system design. Ergonomics (or human factors) is the logical teach concerned with the understanding of intuition among people and other components of a framework, and the profession that applies theory, principles, data and methods to design in order to optimize human well-being and overall system performance. Specialists of ergonomics and ergonomists contribute to the design and evaluation of tasks, jobs, products, environments and systems in order to make them compatible with the needs, abilities and limitations of people. Ergonomics makes a difference by harmonizing things that connect with individuals in terms of people's needs, capacities and confinements.

eISSN: 2398-4287C 2021. The Authors. Published for AMER ABRA cE-Bs by e-International Publishing House, Ltd., UK. This is an open access article under the CC BYNC-ND license (http://creativecommons.org/licenses/by-nc-nd/4.0/). Peer-review under responsibility of AMER (Association of Malaysian Environment-Behaviour Researchers), ABRA (Association of Behavioural Researchers on Asians/Africans/Arabians) and cE-Bs (Centre for Environment-Behaviour Studies), Faculty of Architecture, Planning \& Surveying, Universiti Teknologi MARA, Malaysia.

DOI: https://doi.org/10.21834/ebpj.v6iSl5.2927 


\subsection{Literature Review}

\subsection{Issues of cognitive ergonomics}

In this particular section, three major issues will be discussed, which are the Value of Ergonomics Today, Protocol Analysis as Methodology in Understanding Design Reasoning, and Cognitive Ergonomics in Practice.

\subsubsection{Value of ergonomics today}

Numerous designers in Malaysia have endured since their conditions or capacities when planning unused items (visual appearance of shape) at work and domestically are contradictory to their needs, capacities and confinements. In most cases, the process is characterized as a reflective conversation with materials whose basic structure, seeing-moving-seeing, is an interaction of designing and discovery. For instance, Schön and Wiggins (1992) states that "...the designer sees what is there in some representation of a site, draws in relation to it, and sees what has been drawn, thereby informing further designing." Lakoff and Johnson (1999) state that the most fundamental metaphor Descartes uses is the commonplace "knowing is seeing" metaphor. What Schön is saying is basically the same thing. Designers use visualization as a means of triggering new insights into the material they are working with. The insights may come from schemas or mental models, but they may also be analogies to something else. These circumstances influence their plan considering the handling, as well as that of organizations and social orders. Soaring innovations can make the originators' lives more proficient and energizing. In any case, interest in innovation and excessively yearning trade desires can cause them to miss cognitive ergonomics dangers. Ignoring these dangers can have a genuine impact on the quality of the plan of furniture on producers, providers and benefit enterprises. The challenge in the long run for the originator is choosing where the onus for better procedures on cognitive ergonomics lies: with the company or the workers. This is especially so as the relationship between designers and bosses advance towards shorter, more adaptable courses of action, and as individuals work less from the office and more frequently from domestic and third working places. This problem creates an opportunity for design suppliers to offer programs that pave the way for better cognitive ergonomics at the office, domestic, and third working places to companies and their workers. Subsequently, cognitive ergonomics and human components will be more crucial during the postmodern period than when it was to begin with.

\subsubsection{Protocol analysis as methodology in understanding design reasoning}

Protocol analysis is an experimental and observational investigative strategy. A convention is a possibly recorded piece of an event or moment in time within the way of behaviours (Jiang and Yen, 2009; Newell, 1966). Plan conventions are ordinarily within the frame of recordings of a designer's plain behaviours, such as verbalization, outlines, and audio-visual recordings captured by cameras (Akin, 1984). Methodological talks on non-exclusive convention examination are exceptionally centred on the issues of verbalization, i.e. the legitimacy and completeness of verbal reports and impacts caused by verbal detailing (Abidin, Christoforidou, and Liem, 2009). Be that as it may, plan exercises include numerous visual and spatial components, which cannot be fittingly detailed verbally. Numerous plan scholars not only considered plan mastery to dwell in designers' visual representations; they also expect that visual considering is more pivotal than typical considering in planning forms (Abidin, Warell, and Liem, 2011). Schön (1983) argues that the "language of designing" consists of tightly connected verbal and non-verbal elements. Akin and Lin (1995) proposed dual-mode design thinking, i.e. the coexistence of verbal-conceptual and visual-graphic elements in design activities. The applications of protocol analysis in design research therefore always require incorporating other conventional observational means in order to accommodate non-verbal protocols. The need for a comprehensive audit on the pondering of plan convention and the mixture of plan looks into the strategies which cannot be completely accounted for by the standards of unique verbal convention investigation thus requires an orderly writing survey with a noteworthy test measure. The reason for this audit is to define the state of craftsmanship to see how standard analysts conduct a design protocol analysis.

\subsubsection{Cognitive ergonomics in practice}

Protocol analysis is an empirical, observational research method (Zainal Abidin, Anwar, and Rahim, 2020). A protocol is a piece of record. Delft argues that "...of all the empirical, observational research methods for the analysis of design activity, protocol analysis is the one that has received the most use and attention in recent years (Cross, Christiaans, and Dorst, 1996). It has ended up respected as the foremost likely strategy (maybe the as it were strategy) to bring out into the open to some degree puzzling cognitive capacities of designers". This audit affirms this articulation. Different sorts of conventions, consider settings and investigation approaches were distinguished. Be that as it may, numerous plan conventions consider this strategy as acceptable. According to Jiang and Yen [9], only one third of publications ( $\mathrm{N}=45$ ) explicitly reflected the pros and cons of the method they employed. Most of these reactions rehashed the limitations of bland verbal convention examination; few considered the qualification between plan conventions with unique verbal convention investigation, just like the dual-mode issue that was discussed in the presentation segment. It requires more methodological reflections to create a convention examination that is more fitting to the necessities of plan inquire about. Subsequently, the utilization of convention investigation is anticipated to enhance understanding, where we attempt to capture the vulnerability in the way of thinking of the creator, and put it in a controlled environment. 


\subsection{Findings}

\subsection{Case example of cognitive ergonomics and formgiving}

\subsubsection{Unstructured approaches}

Planning furniture by designers may infer either an organized approach or an unstructured approach. This may be driven by the step towards the natural plan in considering travel. The creator comprises suitably named "Innovation Catalysts," whose part is to work with other creators in the company through their item activities. The idea is not to offer the mastery to illuminate an issue, but maybe to offer the originator and the relevant groups a way to apply plan considering. In this setting, we see the unstructured approach in planning furniture through a hermeneutics handle (see Figure 1). Hermeneutics is a method or principle of interpretation. In this setting, hermeneutics is the art of understanding and making oneself understood. It goes beyond mere logical analysis and general interpretive principles.
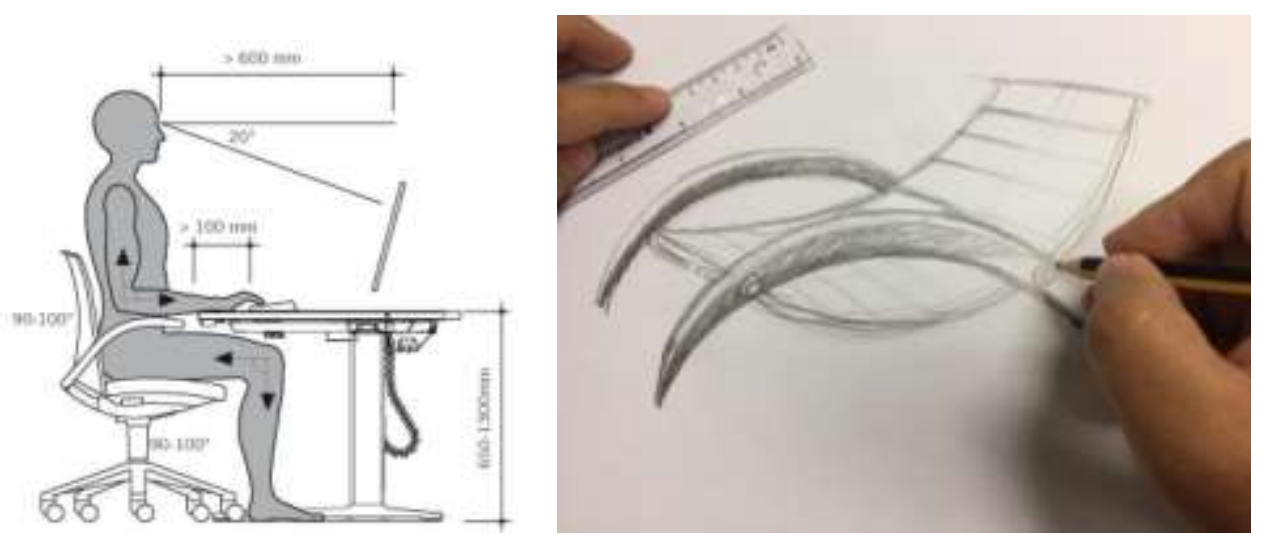

Fig. 1. Unstructured approaches in designing furniture.

Central to this handle is the understanding of both the greater picture in connection to the points of interest, and the points of interest in connection to the greater picture. This understanding develops and changes as we proceed to come over extra points of interest, whether the enormous picture may be a UX extend or something as basic as perusing a book. How can we overcome our preferences and extend our skyline? Gadamer clarifies this through the show of a discussion (Timmer, 2015). In most discussions where we learn something modern, we take after a design: tune in, reflect, ask questions, consider modern illustrations and summarize what we hear. Gadamer recommends this for considering and understanding anything, from an antiquated content to a scholastic paper on interaction plan.

\subsubsection{Human interaction in designing furniture}

Human interaction based on cognitive formgiving (Akner Koler, 2007) or "shaping" is a multidisciplinary field of study focusing on the design (Zainal Abidin, Sigurjónsson, Liem, and Keitsch, 2008) of visual images and, in particular, the interaction between humans (the users) and design (Mohamed Kamil and Abidin, 2015). Where at first concerned with plan, human interaction based on cognitive ergonomics has since extended to cover nearly all shapes of data innovation plans. In spite of that, a few contrasts remain between cognitive-based human interaction and client involvement (UX) plan. UX is the method design groups utilize to make items that give significant encounters to clients. Additionally, it is a part of the hermeneutics approach of human reasoning. This includes the plan of the whole handle of procuring and joining the item from the perspectives of branding, plan, ease of use and work. Specialists in cognitivebased human interaction tend to be more scholastically focused (Abidin, Othman, Shamsuddin, Samsudin, Hassan, and Mohamed, 2016). 
Table 1. Image interaction design at different levels of abstraction

\begin{tabular}{|c|c|c|c|c|}
\hline \multirow{2}{*}{$\begin{array}{l}\text { Protocol } \\
\text { time }\end{array}$} & \multicolumn{4}{|c|}{ Episode } \\
\hline & $\begin{array}{l}\text { Level of } \\
\text { abstraction }\end{array}$ & Interaction of images & Character & Results \\
\hline 00:05:00 & Abstract & & Line & Sketch the new gestalt \\
\hline 00:10:00 & $\begin{array}{l}\text { Semi- } \\
\text { Concrete }\end{array}$ & & $\begin{array}{l}\text { Concave, } \\
\text { convex, hollow, } \\
\text { dimple }\end{array}$ & Sketch the features \\
\hline 00:15:00 & Concrete & & $\begin{array}{l}\text { Primitive } \\
\text { objects }\end{array}$ & Sketch the component \\
\hline
\end{tabular}

It is included in logical investigation and creating experimental understanding of clients. On the other hand, UX creators are nearly constantly industry-focused and included in building items or administrations, e.g. smartphone apps and websites. This notwithstanding, the viable contemplations for items that we as UX experts are concerned with have coordinate joins to the discoveries of human interaction based on cognitive advantages, which are almost real user-centric mindsets. With the broader span of subjects that is covered by cognitive-based human interaction, UX designers have a wealth of assets to draw from, in spite of the fact that much investigation remains suited to scholarly groups of onlookers. Those of us who are designers too need the extravagance of time, which human interaction based on cognitive pros ordinarily appreciate. So, we must extend past our industry-dictated imperatives to get to these more scholastic discoveries. Once designers can do that, they can use key bits of knowledge to accomplish the most excellent plans for their clients. By "collaborating" in this way with human interaction based on the cognitive world, creators can drive impactful changes within the showcase and society. The technique of visual convention investigation has been utilized to get the originator's natural consideration related to the cognitive ergonomics perspective. The employments of 15 minute video perceptions based on short-term memory shows how originators reflect properties of shape, i.e., gestalt, features, and components of a shape on the off-chance that a few objects will be utilized by a designer as a disposition board or impact board (Mohamed Kamil, Abidin, and Hassan, 2018). Within the perceptions of speedy portrayals at a diverse level of deliberation, we found that the originator communicates with the data to characterize a concept. The designer is considering and investigating conceivable plan arrangements to extend shape variety (Abidin, Bjelland, and Øritsland, 2008). At the same time, the originator looked at visual pictures before him to legitimize the ultimate appearance of item. We found that the concept of a strong structure beneath the surface of the item body (also called "a bone line") characterizes the gestalt plan of the item (see Table 1). This appears to be in line with Monö's (1997) depiction of frame as a portion of gestalt, where for him gestalt is a course of action of parts which show up and function as more than the whole of its parts. The symbolism is epitomized within the unstructured approach of visual considering that consequently happens with plan portrayals (Chumiran, Abidin, Anwar, Vermol, and Sirat, 2020). Plan outlines involve the same time cuts when they share meanings and have the same connections to setting (Chumiran, Abidin, and Mohamed Kamil, 2020). It may be a significant mistake to think of visual as a code or "sketches language," isolated from frame dialect.

\subsection{Discussion}

\subsection{Level of complexity in design}

Plans can have complexity in methodology and strategies. In spite of the fact that each of these components can be complex, it is their combination that can cause the high levels of complexity that produces plan handles which are difficult to attain and control. This 
complexity can be conceptualised and portrayed through a number of formal approaches that deliver knowledge of the conduct of designs and plan forms. In any case, there's no bound-together hypothesis of complexity, and no single hypothesis captures all angles of a complex framework. Furniture plan draws give illustrative cases of plan complexity. For complexity emerging from the interaction of the item and handle, consider the useful and secluded groupings in components. The back rest and legs are commonly outlined by isolated groups. The impact of plan choices normally made by personal space specialists is clear in the model test. On the one hand, the decoupling of forms diminished complexity in planning, but on the other hand expanded complexity within the item and its conduct, presenting startling 'emergent' conduct. Undesirable new conduct is, along these lines, evacuated from the plan. Rising conduct emerges ceaselessly as a plan continues from concept to exemplification and make. In a few cases, this development speaks to unused revelation and motivation for plan advancements, while in other domains such as designing, the method of design is to iteratively expel undesirable rising practices. The ultimate plan has, in framework energetic and data faculties, negligible complexity.

\subsection{Cognitive ergonomics and furniture design}

Unused plan and concept of furniture plan can give an advantage to the honing creator in moving the standard forward, and to advance mindfulness in terms of security and wellbeing of ergonomics in Malaysia. Different sorts of furniture plan were utilized by furniture creators. From our perception, the planning of furniture was non-standardized, where the details were fundamentally utilized. From the estimation of the existing furniture, the results concluded that the current situation coordinates with the scene of convention time interaction between pictures and highlights estimations. Within the advancement of frame based on cognitive ergonomics furniture, the prepared furniture plan was coordinated with the cognitive ergonomics concept to deliver a modern furniture plan for Malaysians. The prepared furniture plan was based on cognitive ergonomics, and the security was distinguished by a creator. It comprised a proposed plan concept after the creation and demonstration of a mock-up, and manufacturing of a model. Subsequently, it is suspected that the numerous individuals who call that "unstructured way of thinking" as a prerequisite for development are befuddling advancement and imagination. For one who considers development as innovation (an item of imaginative considering) taken after by usage (basically extended administration), advancement can't be unstructured. That being said, is the creator prepared to capitulate to the numerous reasons on why the imaginative considering component of development is totally unstructured?

\subsection{Advantages in design education}

The idea that planning a furniture plan makes one "a much better; a higher; a stronger; an improved" originator is debatable. There are parts of components that make the environment of a plan handle more conducive to the imagination, and a better approach of considering such as: 1) Organized versus Unstructured considering (Creator investigates the thought of "What can be done" more than "What has been done". Understudies are presented to different strategies to think in an unexpected way and "out of the box". Besides, inventiveness isn't a blessing individuals are said to be born with, but a skill that can be developed); 2) Multi-disciplinary environment (Designers more often than not have different programs running within the same campus. This closeness to understudies in other disciplines cultivates other ways of looking at things, and the conversion of distinctive individuals, thoughts and strategies can provide birth to modern concepts and items); 3) Addressing everything (A huge portion of the designer goes into "unlearning" what you've learnt. Depending on your age, background and childhood, it can be a really difficult errand. Plan school tries to instruct you to look at things from a fair-minded, new and non-judgmental way and to disregard biased ideas. Easier said than done, but an awfully basic way of looking at concepts when re-designing items or indeed administrations); 4) Edge whereas work looking for (The design community around the world may be a much smaller community when compared to administration or designing); and 5) Certainty (This is often something that we have actually witnessed numerous times). Self-taught originators take time to develop certainty that designers as a rule have inserted in them. Self-taught creators find it difficult to demonstrate their merits to create the need for a plan of instruction.

\subsection{Conclusions}

The portrayal of the conceivable conduct of a 'well-behaved' plan is straightforward. Here, issues may include the creator attempting to understand the requirements for a successful solution that must be met, and the criteria that designers apply to choose the finest arrangement. In doing this, the originator must be inventive, startling, erratic, exceptional, uncontrolled, strong, wild, out of the box and out of hand, and unstructured as well, of course. Originators for the most part maintain a strategic distance from eminent conduct, which is arbitrary and chaotic by finding plans inside edges. Ideal or tall performing plans work near edges, where conduct gets to be exceptionally erratic or chaotic. A few complexity issues happen here. To begin with, startling intelligence between parts may cause conduct to pass over the edge. It may be that diminishments in plan prepare complexity through seclusion, which provides this higher plan complexity in conduct. Third, a plan features a parameter envelope in which the plan performs typically. The metaphorical form is embodied, and it is imperative for designers to imagine something from an unstructured visual frame verifiably into an expressly unmistakable shape.

\section{Acknowledgements}

This research is gratefully supported by Universiti Teknologi MARA [Grant number: 600-IRMI/MYRA 5/3/REI (002/2018)]. 


\section{References}

Abidin, S. Z., Bjelland, H. V., \& Øritsland, T. A. (2008). The embodied mind in relation to thinking about form development. In Proceedings of NordDesign 2008 Conference (pp. 265-274)

Abidin, S. Z., Christoforidou, D., \& Liem, A. (2009). Thinking and re-thinking verbal protocol analysis in design research. In DS 58-2: Proceedings of ICED 09, the 17th International Conference on Engineering Design (Vol. 2, pp. 1-12)

Abidin, S. Z., Othman, A., Shamsuddin, Z., Samsudin, Z., Hassan, H., \& Mohamed, W. A. W. (2016). Identifying sequence maps or locus to represent the genetic structure or genome standard of styling DNA in automotive design. Advances on Mechanics, Design Engineering and Manufacturing, 1159-1166. doi:10.1007/978-3-319-457819_116

Abidin, S. Z., Warell, A., \& Liem, A. (2011). The significance of form elements: A study of representational content of design sketches. In Proceedings of the DESIRE'11 Conference on Creativity and Innovation in Design (pp. 21-30). DOI: 10.1145/2079216.2079219

Akin, O. (1984). An Exploration of the Design Process. In Cross, N. (Ed.), Developments in Design Methodology: John Wiley \& Sons Ltd, pp 189-207.

Akin, O., \& Lin, C. (1995) Design protocol data and novel design decisions. Design Studies, vol. 16, no. 2, pp 211-236.

Akner Koler, C. (2007). Form \& Formlessness, questioning aesthetic abstractions through art projects, cross- disciplinary studies and product design education. Doctoral thesis, Stockholm: Axlbooks.

Chumiran, M. H., Abidin, S. Z., Anwar, R., Vermol, V. V., \& Sirat, A. (2020). 3R Evokes Ecodesign Identity in Ecological System of Green Manufacturing. International Journal of Supply Chain Management. 9(3), pp. 182-190.

Chumiran, M. H., Abidin, S. Z., \& Mohamed Kamil, M. J. (2020). Pre-Post Observation Research Fosters a Preliminary Study in Product Form Identity. In L., Buck, E. Bohemia, \& H. Grierson, Proceedings of the 22nd International Conference on Engineering and Product Design Education, E and PDE 2020 Institution of Engineering Designers, The Design Society.

Cross, N., Christiaans, H., \& Dorst, K. (1996). Introduction: The Delft Protocols Workshop. In Cross, N., Christiaans, H., and Dorst, K. (Eds.), Analysing Design Activity. Chichester: John Wiley \& Sons Ltd, pp 1-16

International Ergonomics Association (2019). Retrieved from https://www.iea.cc/whats/

Jiang, H., \& Yen, C. C. (2009). Protocol Analysis in Design Research: a review. Proceeding of IADSR 2009

Lakoff, G., \& Johnson, M. (1999). Philosophy in the flesh: The embodied mind and its challenge to western thought. New York: Basic Book, p. 35.

Mohamed Kamil, M. J., \& Abidin, S. Z. (2015). Unconscious interaction between human cognition and behavior in everyday product: A study of product form entities through free hand sketching using the design syntactic analysis. Proceedings of the 17th International Conference on Engineering and Product Design Education (E\&PDE15), Great Expectations: Design Teaching, Research \& Enterprise, Loughborough, UK, 03-04.09.2015 (p.369-374).

Mohamed Kamil, M. J., Abidin, S. Z., \& Hasdinor Hassan, O. H. (2018). The investigation of designers' Reflective Practice Activity Using Verbal Protocol Analysis Proceedings of the 20th International Conference on Engineering and Product Design Education (E\&PDE 2018), Dyson School of Engineering, Imperial College, London. 6th - 7th September 2018, (p. 363-368).

Monö, R. (1997). Design for product understanding. Stockholm: Liber.

Newell, A. (1966). On the Analysis of Human Problem Solving Protocols, in International Symposium on Mathematical and Computational Methods in the Social Sciences. Rome, Italy, pp 145-185.

Schön, D. A. (1983) The Reflective Practitioner: How professionals think in action, London Temple Smith. 374.

Schön, D. A. \& Wiggins, G. (1992). Kind of seeing and their functions in designing, Design Studies, 16 (3), pp. 135-156

Timmer, S. (2015). Hermeneutics for designers. Retrieved from https://www.uxbooth.com/articles/hermeneutics-for-designers/

Zainal Abidin, S., Anwar, R., \& Rahim, W. N. (2020). The Presence of Fibonacci Sequence in Malaysia Keris Design Related to Elements of Art and Principles of Design. Environment-Behaviour Proceedings Journal, 5(SI3), 141-147.

Zainal Abidin, S., Sigurjónsson, J., Liem, A., \& Keitsch, M. (2008). On the role of formgiving in design. In DS 46: Proceedings of E and PDE 2008, the 10th International Conference on Engineering and Product Design Education. 